\title{
Study on the Bearing Capacity of Autoclaved Fly Ash Masonry Short Column
}

\author{
Xiaoxin YANG ${ }^{1, a^{*}}$, Jianrong YANG ${ }^{1, b}$, Zhichao PENG ${ }^{1, c}$ \\ ${ }^{1}$ Kunming University of Science and Technology, Kunming 650500, China \\ a 862634523@qq.com, b332970794@qq.com, c842764996@qq.com
}

\begin{abstract}
Keywords : Autoclaved fly ash (AFA). Masonry structure; Bearing capacity. Stress-strain relation
Abstract. According to the plane cross-section assumption and static equilibrium, the formulas for the bearing capacity of autoclaved fly ash masonry short column (AFAMC) can be deduced. And in the deducing process, we should consider the stress-strain relations of the various masonry materials. In this paper, the experimental values of bearing capacity of the short column are compared with those from the theoretical formulas. The data coincidence will verify the reasonability of the formulas deduced by the author. The experimental values of bearing capacity are also compared with the values calculated under the formula of Code for Design of Masonry Structures (GB50003-2011). It can be found the theoretical values are higher than experimental values. So the compression bearing capacity of AFAMC based on the code is overestimated which leads to insecurity.
\end{abstract}

\section{Introduction}

At present, the formula of the bearing capacity $\mathrm{N}$ of masonry column is the product of section area A, compressive strength $f$ and eccentric influence coefficient ${ }^{\varphi}$. Researche shows that axial offset $e$ and component of high thickness ratio $\beta$ are the main factors affecting the coefficient of eccentric compression member $\varphi$. The influence coefficient is the major factor that affects the bearing capacity [6].

In this paper, different formulas of AFA bearing capacity and eccentricity influence coefficient expressions were deduced and the theoretical value were calculated according to the stress-strain relationship of the masonry. And the theoretical data were compared with experimental data [1], the data comparison results in good agreement, it shows that the method of derivation is desirable and the stress-strain relationship is reasonable in the compression of masonry structures in this paper. Finally, it is verified that the calculation formula of the load bearing capacity of the standard is reasonable or not by experimental data.

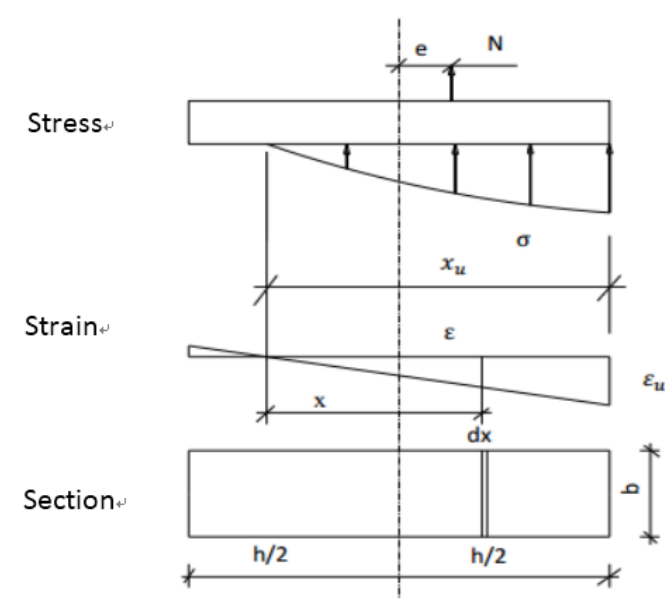

Fig. 1 Stress curve distribution section analysis

\section{The stress-strain relations of AFAMC}

According to the experimental data of the strain in the cross section with AFA masonry specimen [1]: the stress in the cross section of AFAMC isn't linear until it is destroyed and it can be accorded with the plane cross-section assumption well. At the same time, since the tensile strength of masonry structure is very low, the horizontal cracks will be immediately out of work. Thus the tensile strength of the AFA masonry can be neglected. Due to high stress gradient in the eccentric compression section, the plastic zone development is greater than the axial pressure. Therefore, the stress-strain curve of eccentric compression is replaced by the stress-strain curve of axial compression [2] is on the safe side, as shown in Fig. 1.

The peak pressure strain $\varepsilon_{0}$ refers to the masonry compressive stress reached the peak of the 
longitudinal strain values; masonry structure is one of the important parameters of stress-strain curve. References [3] provide the peak compressive strain is between 0.0026 and 0.0049 . It also lists several groups of masonry under uniaxial compressive stress-strain curve, comprehensive analysis of $\varepsilon_{0}$ value 0.003 . References [3] points out that the disparity of the rise of various types of stress-strain curves is not big, the disparity of various types of brick masonry is big, and the ratio of the ultimate compressive strain to the peak pressure strain $\varepsilon_{u} / \varepsilon_{0}$ for all kinds of AFA masonry is 1.6 .

\section{Formula of compressive bearing capacity for AFAMC}

Depending on the stress - strain relations, derivation the formula of compression capacity $\mathrm{N}$ and eccentricity influence coefficient $\varphi$, also lists the formula given in the specification [6].

Krishna Naraine, Sachchidanand Sinha proposed the model of stress-strain relationship [3]:

$$
\frac{\sigma}{f_{m}}=\frac{\varepsilon}{\varepsilon_{0}} \cdot e^{\left(1-\frac{\varepsilon}{\varepsilon_{0}}\right)}
$$

From Fig. 1, the above conditions can be:

$$
\frac{\varepsilon_{u}}{\varepsilon_{0}}=1.6
$$

Obtained by the proportional relationship:

$$
\begin{aligned}
& \frac{\varepsilon_{\mathrm{O}}}{\varepsilon_{u}}=\frac{x_{\mathrm{O}}}{x_{u}}=\frac{1}{1.6}=0.625 \\
& \frac{\varepsilon_{\mathrm{O}}}{x_{\mathrm{O}}}=\frac{\varepsilon_{u}}{x_{u}}=\frac{\varepsilon}{x}
\end{aligned}
$$

It's derived from static equilibrium condition of the cross section:

$$
\begin{aligned}
& N_{1}=\int_{0}^{x_{u}} f_{m} \cdot \frac{\varepsilon}{\varepsilon_{\mathrm{O}}} e^{\left(1-\frac{\varepsilon}{\varepsilon_{\mathrm{O}}}\right)} \cdot \boldsymbol{b} \cdot d x \\
& N_{1}\left(\frac{h}{2}+e\right)=\int_{0}^{x_{u}} f_{m} \cdot \frac{\varepsilon}{\varepsilon_{\mathrm{O}}} e^{\left(1-\frac{\varepsilon}{\varepsilon_{\mathrm{O}}}\right)} \cdot b \cdot\left(h-x_{u}+x\right) d x
\end{aligned}
$$

From Eq. 3, Eq. 4, Eq. 5, Eq. 6:

$$
N_{1}=\varphi_{1} f_{m} b h \quad \varphi_{1}=0.8100\left(1-\frac{2 e}{h}\right)
$$

In the formula:

$f_{m}$ - Average compressive strength of masonry;

$\varepsilon_{0}$ - Strain of $f_{m}$;

$h$ - The length of rectangular cross-section eccentric axial force direction, When the axial compression of the column cross-section smaller side length;

$b$ - Sectional width;

$e$-Axial force eccentricity

$N_{1}$ - Compressive bearing capacity;

$\varphi_{1}$-Eccentric influence coefficient.

Stress - strain relation model proposed by Professor Shi Chuxian of Hunan University [4]:

$\frac{\sigma}{f_{m}}=\frac{9}{10}\left(1-e^{-2.3 \frac{\varepsilon}{\varepsilon_{0}}}\right)$ 
It's derived from static equilibrium condition of the cross section:

$$
N_{2}=\int_{0}^{x_{u}} f_{m} \frac{9}{10}\left(1-e^{-2.3 \frac{\varepsilon}{\varepsilon_{0}}}\right) b \cdot d x \quad \varphi_{2}=8 \boldsymbol{0}\left(\boldsymbol{\theta}-\frac{2 e}{h}\right)
$$

From Eq. 2, Eq. 3, Eq. 4, Eq. 9, Eq. 10

$$
N_{2}=\varphi_{2} f_{m} b h \quad \varphi_{2}=8 \propto\left(\Theta-\Theta \frac{2 e}{h}\right)
$$

OIn the formula:

$\mathrm{N}_{2}$ - Compressive bearing capacity;

$\varphi_{2}$-Eccentric influence coefficient.

Turnsek and Cacovic proposed model of stress-strain relationship [5]:

$\frac{\sigma}{f_{m}}=6.4\left(\frac{\varepsilon}{\varepsilon_{0}}\right)-5.4\left(\frac{\varepsilon}{\varepsilon_{0}}\right)^{1.17}$

It's derived from static equilibrium condition of the cross section:

$$
\begin{aligned}
& N_{3}=\int_{0}^{x_{u}} f_{m}\left[6.4\left(\frac{\varepsilon}{\varepsilon_{0}}\right)-5.4\left(\frac{\varepsilon}{\varepsilon_{0}}\right)^{1.17}\right] b d x \\
& N_{3}\left(\frac{h}{2}+e\right)=\int_{0}^{x_{u}} f_{m}\left[6.4\left(\frac{\varepsilon}{\varepsilon_{0}}\right)-5.4\left(\frac{\varepsilon}{\varepsilon_{0}}\right)^{1.17}\right] \cdot b \cdot\left(h-x_{u}+x\right) d x
\end{aligned}
$$

From Eq. 2, Eq. 3, Eq. 4, Eq. 9, Eq. 10, Eq. 15, Eq. 16:

$$
N_{3}=\varphi_{3} f_{m} b h \quad \varphi_{3}=9 \theta\left(-\frac{2 e}{h}\right)
$$

In the formula:

$\mathrm{N}_{3}$ - Compressive bearing capacity;

$\varphi_{3}$ - Eccentric influence coefficient.

The formula of the pressure bearing capacity and the eccentric influence factor according to the specification [6]:

$$
N_{4}=\varphi_{4} f b h
$$

When $\beta \leq 3$

$$
\begin{aligned}
\varphi_{4} & =\frac{1}{1+12\left(\frac{e}{h}\right)^{2}} \\
\varphi_{0} & =\frac{1}{1+\alpha \beta^{2}}
\end{aligned}
$$$$
\text { When } \beta \geq 3
$$$$
\varphi_{4}=\frac{1}{1+12\left[\frac{e}{h}+\sqrt{\frac{1}{12}\left(\frac{1}{\varphi_{\mathrm{O}}}-1\right)}\right]^{2}}
$$

In the formula:

$N_{4}$ - Compressive bearing capacity;

$\varphi_{4}$-Eccentric influence coefficient

$\varphi_{0}$ - The stability coefficient of axially loaded members;

$\alpha$ - Coefficient related to the strength of mortar;

$\beta$-Component of high thickness ratio;

\section{Experime ntal Verification}

The eccentric compression force is one of the main forms of masonry structures. Eccentric compression test of 52 masonry specimens of the AFA brick in reference [1] and recorded the failure load and sectional stress distribution under different loads. According to the needs of this article, only selected 24 experiment result values and analyzed. 
Table 1 Eccentric compression of AFA solid masonry bearing capacity test comparison with the theore tical value

\begin{tabular}{|c|c|c|c|c|c|c|c|c|c|}
\hline \multicolumn{2}{|c|}{ Test value (Failure load) } & \multicolumn{2}{|c|}{ Formula (7) } & \multicolumn{2}{|c|}{ Formula (12) } & \multicolumn{2}{|c|}{ Formula (17) } & \multicolumn{2}{|c|}{ Formula (19) } \\
\hline$\underline{e}$ & $N_{u}$ & $N_{1}$ & $N_{1}$ & $N_{2}$ & $N_{2}$ & $N_{3}$ & $N_{3}$ & $N_{4}$ & $N_{4}$ \\
\hline $\bar{h}$ & $\mathrm{kN}$ & $\mathrm{kN}$ & $\overline{N_{u}}$ & $\mathrm{kN}$ & $\overline{N_{u}}$ & $\mathrm{kN}$ & $\overline{N_{u}}$ & $\mathrm{kN}$ & $\overline{N_{u}}$ \\
\hline 0 & 757.0 & 710.9 & 0.939 & 613.3 & 0.810 & 712.5 & 0.941 & 747.7 & 0.988 \\
\hline 0 & 713.5 & 670.2 & 0.939 & 578.2 & 0.863 & 671.7 & 0.941 & 704.9 & 0.988 \\
\hline 0 & 721.3 & 676.9 & 0.938 & 584.7 & 0.811 & 679.2 & 0.942 & 712.8 & 0.988 \\
\hline 0.1 & 581.0 & 542.2 & 0.933 & 467.8 & 0.805 & 542.7 & 0.934 & 592.7 & 1.020 \\
\hline 0.1 & 565.8 & 546.2 & 0.965 & 471.1 & 0.834 & 546.5 & 0.967 & 596.8 & 1.055 \\
\hline 0.1 & 567.0 & 546.8 & 0.964 & 471.8 & 0.832 & 547.3 & 0.965 & 597.7 & 1.054 \\
\hline 0.2 & 411.4 & 406.1 & 0.987 & 350.4 & 0.852 & 407.1 & 0.990 & 433.9 & 1.055 \\
\hline 0.2 & 454.5 & 409.0 & 0.900 & 352.8 & 0.776 & 409.9 & 0.902 & 437.0 & 0.961 \\
\hline 0.2 & 406. 0 & 405.5 & 0.999 & 349.9 & 0.862 & 406.5 & 1.001 & 433.3 & 1.067 \\
\hline 0.3 & 285.8 & 270.4 & 0.946 & 233.2 & 0.816 & 271.1 & 0.949 & 307.0 & 1.074 \\
\hline 0.3 & 277.5 & 272.7 & 0.983 & 235.2 & 0.848 & 273.3 & 0.985 & 309.6 & 1.116 \\
\hline 0.3 & 309.1 & 271.9 & 0.880 & 234.5 & 0.759 & 272.5 & 0.882 & 308.7 & 0.999 \\
\hline Average & & & 0.948 & & 0.822 & & 0.950 & & 1.030 \\
\hline $\begin{array}{l}\text { Coefficient } \\
\text { of variation }\end{array}$ & & & 0.037 & & 0.040 & & 0.037 & & 0.045 \\
\hline
\end{tabular}

Table 2 AFA porous masonry bearing capacity of eccentric compression test and the comparis on between theoretical values

\begin{tabular}{|c|c|c|c|c|c|c|c|c|c|}
\hline \multicolumn{2}{|c|}{ Test value( Failure load) } & \multicolumn{2}{|c|}{ Formula (7) } & \multicolumn{2}{|c|}{ Formula（12） } & \multicolumn{2}{|c|}{ Formula (17) } & \multicolumn{2}{|c|}{ Formula (19) } \\
\hline$\underline{e}$ & $N_{u}$ & $N_{1}$ & $N_{1}$ & $N_{2}$ & $N_{2}$ & $N_{3}$ & $N_{3}$ & $N_{4}$ & $N_{4}$ \\
\hline $\bar{h}$ & $\mathrm{kN}$ & $\mathrm{kN}$ & $N_{u}$ & $\mathrm{kN}$ & $N_{u}$ & $\mathrm{kN}$ & $N_{u}$ & $\mathrm{kN}$ & $N_{u}$ \\
\hline$\overline{0}$ & 524.4 & 492.1 & 0.938 & 424.8 & 0.810 & 492.9 & 0.940 & 516.0 & 0.984 \\
\hline 0 & 500.0 & 469.4 & 0.939 & 405.2 & 0.810 & 470.2 & 0.940 & 492.2 & 0.984 \\
\hline 0 & 553.4 & 518.9 & 0.938 & 448.0 & 0.810 & 519.9 & 0.939 & 544.2 & 0.983 \\
\hline 0.1 & 385.6 & 394.2 & 1.022 & 340.1 & 0.882 & 395.1 & 1.025 & 428.6 & 1.112 \\
\hline 0.1 & 432.5 & 395.3 & 0.914 & 341.1 & 0.789 & 396.2 & 0.916 & 429.8 & 0.994 \\
\hline 0.1 & 387.9 & 398.1 & 1.026 & 343.4 & 0.885 & 399.0 & 1.029 & 432.8 & 1.116 \\
\hline 0.2 & 274.2 & 297.3 & 1.084 & 256.5 & 0.935 & 298.0 & 1.087 & 315.4 & 1.150 \\
\hline 0.2 & 344.0 & 296.9 & 0.863 & 256.1 & 0.745 & 297.5 & 0.865 & 315.0 & 0.916 \\
\hline 0.2 & 328.8 & 298.1 & 0.907 & 257.2 & 0.782 & 298.8 & 0.909 & 316.3 & 0.962 \\
\hline 0.3 & 234.7 & 197.1 & 0.840 & 170.1 & 0.725 & 197.6 & 0.842 & 222.3 & 0.947 \\
\hline 0.3 & 280.1 & 198.2 & 0.708 & 171.0 & 0.610 & 198.7 & 0.709 & 223.5 & 0.798 \\
\hline 0.3 & 204.7 & 197.1 & 0.963 & 170.1 & 0.831 & 197.6 & 0.965 & 222.3 & 1.086 \\
\hline Average & & & 0.929 & & 0.801 & & 0.931 & & 1.003 \\
\hline $\begin{array}{l}\text { Coefficient of } \\
\text { variation }\end{array}$ & & & 0.105 & & 0.106 & & 0.106 & & 0.099 \\
\hline
\end{tabular}


The average value of the single brick compressive strength were $16.77 \mathrm{MPa}$ and $10.46 \mathrm{MPa}$ which the AFA solid brick and porous brick were choosed in the experiment. Measuring the compressive strength of the mortar respectively $13.69 \mathrm{MPa}$ and $19.08 \mathrm{MPa}$. Solid brick masonry outer contour size specimens are $240 \mathrm{~mm} \times 365 \mathrm{~mm} \times 746 \mathrm{~mm}, \quad \beta=3.108$; perforated brick is $240 \mathrm{~mm} \times 365 \mathrm{~mm} \times$ 790mm, $\beta=3.290 . \mathrm{Up}$ and down with the top surface of $10 \mathrm{~mm}$ thick cement mortar. Eccentricity value $e / h$ respectively $0,0.1,0.2$ and 0.3 . Numerical experiments with the carrying capacity of such as Table 1, Table 2.

The analysis of the data in the table shows that load capacities for AFAMC $e / h$ increases as decreases, from the perspective of the average, the use of the bearing capacity of theory and experimental method derived herein determined value better fit, while bearing capacity of the theoretical value of the use of standardized methods of seeking larger than the experimental values, both in the coefficient of variation are relatively stable.

\section{Summary}

Based on the study of 24 AFAMCs, the experiment result show that masonry columns under compression and effects of various factors on bearing capacity of its situation. Under the same assumption, depending on the different stress-strain constitutive relations derived different formulas about compressive bearing capacity and eccentric influence coefficients. By comparing the theoretical data and experimental data of bearing capacity, the results are as follows:

(1) The calculation of Eq. 7, Eq. 12, Eq. 17 compressive bearing capacity values are close to experimental values and the coefficient of variation is stable. In order to verify the correctness of the method and the rationality of the stress-strain relationship of the three kinds of masonry structures.

(2) According to the the current code formula (19), the calculated compression bearing capacity is slightly larger than the experimental values. Aiming at AFAMC, from the calculation of the average can be drawn, the calculation of the load bearing capacity in code is overestimated, may have some defects in the design, and is expected to further revise. It may lead to some flaw in the design, look further amended

\section{References}

[1] Xun Chunyi. Experimental Theoretical Research on the Mechanics Behavior of Autoclaved Fil Ash Brick Masonry [D], College of civil engineering, Dalian University of Science and Technology, 2011.

[2] Qin Shihong, Ni Xiaojun, Cao Huanming. Study on the Stress Strain Curve of Coal Ash Brick Masonry [J]. Journal of Architectural Struc ture:2010, 31 (8) 94-100

[3] Liu Guiqiu. The Research on the Basic Mechanical Behavior of Masonry Structure [D]. College of Civil Engineering, Hunan University, 2005.

[4] K.Naraine, S.Sinha, Behavior of brick masonry under cyclic compressive loading [J]. J. Structure. Engrg ASCE, 115(6), 1989:43-48.

[5] Yang Jianwen,Wu Wentao. Infinitive Computing Model to Explore the Compressive Strength of Masonry [J]. Building Structure, 2004(9), 60-62.

[6] GB50003-2011 Code for Masonry Structure Design[S]. Beijing: China Building Industry Press, 2011. 